\title{
Partial Discharge detection in smart grid using Software Defined Radio
}

\author{
Hamd Mohamed, Member IEEE, Pavlos I. Lazaridis, Senior Member IEEE, Umar Khan, \\ Bahghtar Saeed, Member IEEE, Keyur Mistry, Member IEEE, David Upton, Member IEEE, Peter J. \\ Mather, Member IEEE, and, Ian A. Glover, Member IEEE
}

\begin{abstract}
Smart grid is the term used to describe the next generation power grid in which the management of electricity distribution is enhanced by advanced two-way communications, so that it monitors, protects, and takes decisions automatically to optimize the operation of its interconnected elements. The smart grid is made possible by combining two-way communications and persistent computing capabilities, to enhance control, efficiency, reliability, and safety. Using two-way digital technologies, a smart grid can transport electricity between suppliers and consumers. Such technology allows consumers to save energy, reduce cost and increase their smart appliances' efficiency, reliability and transparency. Software Defined Radio (SDR) is a promising technology, it can support the smart grid so that it can provide control, protection and automatic optimization to operate its interconnected elements effectively and efficiently. This paper proposes the use of Software Defined Radio (SDR) for Partial Discharge (PD) detection and localization at the user end in the smart grid.
\end{abstract}

Keywords - Software Defined Radio, RTL-SDR dongles, Received Signal Strength, Partial Discharge.

\section{INTRODUCTION}

Smart grid technology ranges from traditional central generators and/or emerging renewal distributed generators, which connects the transmission network and distribution system to industrial consumers and domestic users with their home equipment, electric vehicles, and intelligent appliances [1]. Bi-directional connection of electricity and information flows characterizes a smart grid. The information flows establish an automatic and widely distributed delivery network. Through these, the benefits of real-time information enable the nearinstantaneous balancing/management of supply and demand. [2].

The present electric power delivery infrastructure cannot provide such advantages effectively. The smart grid consists of large-scale and small-scale distributed

The authors acknowledge the Engineering and Physical Sciences Research Council for their support of this work under grant EP/J015873/1.

Hamd M. Mohamed, Pavlos I. Lazaridis, Umar Khan, K. Mistry Bahghtar Saeed, David Upton, Peter Mather and Ian A. Glover are with the School of Computing and Engineering, University of Huddersfield, Queensgate, Huddersfield HD1 3DH, UK (e-mail: Hamd.Mohamed@hud.ac.uk). generation which is connected by a high voltage network of transmission lines. As it is well known, the flow of power in the traditional power system (distribution) is principally in one direction.

In the smart grid, the direction of power flow may be in either direction. The smart grid does not depend only on the support of large central-station generation but incorporates significant electric energy storage and distributed energy generation.

Today's households are already host to industrial and smart home appliances, which could make expenses on energy consumption rise. Consumers nonetheless, can be advised to adjust with their energy usage in order to cut back on costs, such as using renewable energy and avoid consuming energy on peak hours. Conventional carbon fuel-based power plants work together with developing distributed renewable energy resources such as wind and the solar. Renewable resources reduce the consumption of carbon fuel and subsequent emission of greenhouse gases. An essential component of the smart grid is an accessible and universal communication infrastructure. The improvement in performance, reliability, security and economy that a smart grid enjoys over a conventional grid relies on and derives from its communication infrastructure. The electricity is distributed in the smart grid between generators and end users. The generators refer to distributed generation sources, while the end users are the industrial, commercial and residential consumers. The distribution is made possible through bi-directional information flow, which will control the consumer smart appliances and allow them to reduce energy consumption [4].

\section{Problem Statement}

The smart grid communication infrastructure can be supported by several technologies, e.g. WiMAX, power line carrier, traditional twisted-copper phone line, microwave radio relay, satellite, cellular, fiber optic cable, as well as short range technologies such as Wi-Fi, ZigBee and Wireless HART. Smart grid communication technologies can be grouped into five areas, namely: advanced components, sensing and measurement, improved interfaces and decision support, standards and groups, and integrated communications. In order to add intelligence to the current power system, a smarter asset monitoring infrastructure is required. Wireless technologies have made it possible to monitor, measure, and detect changes in physical phenomena in electric 
power systems and also in all parts of the smart grid. One important such phenomenon is partial discharge (PD).

The term PD refers to an electrical discharge that only partially bridges the insulation between conductors. Discharge can be of various types including internal, external or surface discharge.

PD activity in a cable depends upon applied voltage, dielectric constant of material and size of the void. These are considered as the factors affecting partial discharge in significant transformer components and distribution systems [4]. In general, partial discharge detection and efficient monitoring can play a significant role in the ongoing maintenance of a high-voltage plant and power generation system. Because of the increased regulatory and operational requirements and the large capital value of equipment, the need for an efficient condition monitoring system has become an inevitable need so as to avoid power equipment failure, and optimal assurance for equipment uptime, reliability and quality services [5-10]. In order to ensure optimal power generation and its reliability, the assurance of efficient functioning of the comprising components is required. The efficient detection and monitoring of partial discharge can be of great significance in power generation and transmission systems.
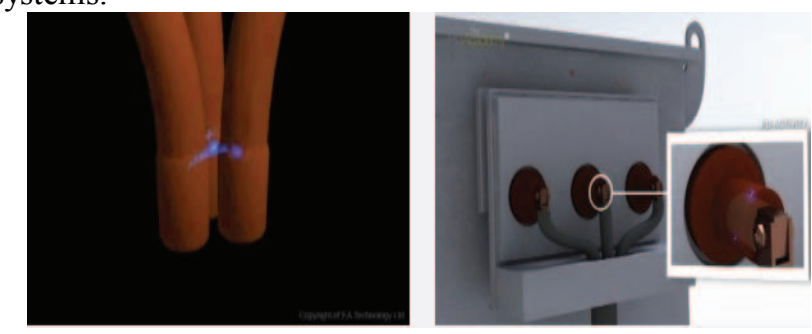

Fig. 1. Examples of PD activity in HV power system. [4]

Figure 1 shows an example of PD activity in electrical power plants and Figure 2 shows the PD activity and when the protection should be activated.

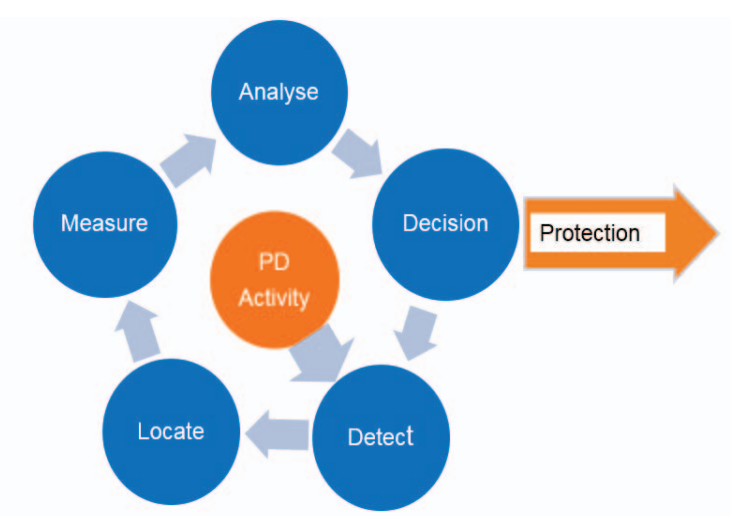

Fig. 2. PD activity and protective action.

PD in electrical systems indicates the presence of foreign material inside the insulation. This foreign material may be a gas filling a void in a solid or liquid dielectric insulator. When two materials with different permittivity (or dielectric constant) are subject to a voltage, the electric field is greatest in the region of smallest permittivity.
Electrical breakdown can occur in this region without occurring elsewhere. Repeated partial discharge further damages the insulation and may eventually result in complete discharge (i.e. flashover). Therefore, a partial discharge measurement should be performed on a regular basis to monitor the integrity of the insulating material [11].

Wireless technologies can be deployed close to the power system equipment to allow a dynamic flow of monitored data. DSP techniques can be utilized and integrated with wireless technologies to design a smart partial discharge (PD) monitoring tool [11-15]. Software Defined Radio SDR is a wireless technology that offers a reliable solution for PD monitoring and localization in the future smart grid. In order to diagnose the nature of a fault within an insulator, the PD monitoring tools monitor PD high frequency RF radiation [16]. This requires processing large data sets with high sampling rates. Important factors such as the number of pulses, their distribution within the power system cycle, pules rise times, peak magnitudes and widths, are required for early detection of PDs. One of the challenging tasks in this project is the use of SDR technology to detect and extract the PD characteristics [17].

\section{USRP As A WIDE BAND SPECTRUM ANALYZER}

Several products are based on SDR technology, however not all of them are compatible to work in a sensor network. USRP SDR series are configurable devices and can be connected in a sensor network. One of this series product is the USRP N200. Due to the hardware limitation of the USRP N200, the USRP cannot scan a frequency band that is larger than its bandwidth (USRP $\mathrm{N} 200 \mathrm{BW}$ is $20 \mathrm{MHz}$ ) in one time, instead this can be done in multistep hence the swept mode is adopted in this work instead of the FFT mode. This is because the PD band of 50-880 MHz is very wide, and in order to scan the whole band, it is required to divide into sub bands and to retune until the whole band is covered [18]. Figure 3 shows the flowchart for the detection operation:

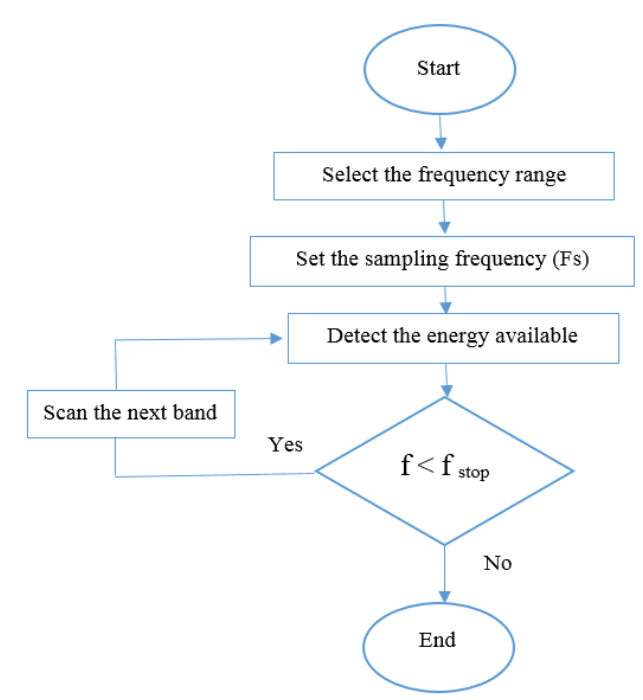

Fig. 3. Flowchart of SDR spectrum scanning. 
In the USRP N200, all samples are sent via a Gigabit Ethernet cable to a PC. These samples are 16-bit I \& Q data (complex values), this means 4 bytes per complex sample. There are two important parameters in the swept modes spectrum analysis:

Tune delay; is the required time for the RF front-end to tune into a new frequency.

Dwell delay; is the required time to determine the average values for each centre tuning frequency.

\section{System Overview And Results}

The PD detection system that is based on SDR is simple as it only consists of a USRP with a wide band antenna and a computer that is connected to the USRP N200 via a Giga Ethernet cable. USRP N200 has been chosen as it is reliable, cost-effective and commonly used for various applications. Figure 4 shows the PD detection system that is based on SDR [19].

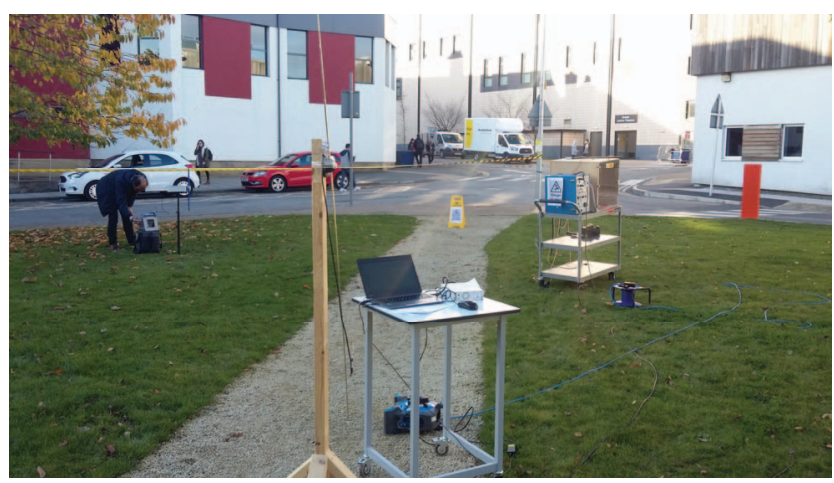

Fig. 4. PD detection system based on SDR.

Figure 5 show the results obtained using the SDR PD detection. Figure 6 shows the results obtained using a spectrum analyzer for validation purposes only. When the results obtained using the SDR PD detection system are compared to those obtained using a spectrum analyzer it is seen that the difference between the two curves (in absence of PD and presence of PD) is identical. It should be mentioned that SDR results are not calibrated, hence the difference in absolute power levels. Obviously a spectrum analyzer demonstrates better results but when we consider the cost it can be appreciated that the SDR system is more cost effective for PD detection.

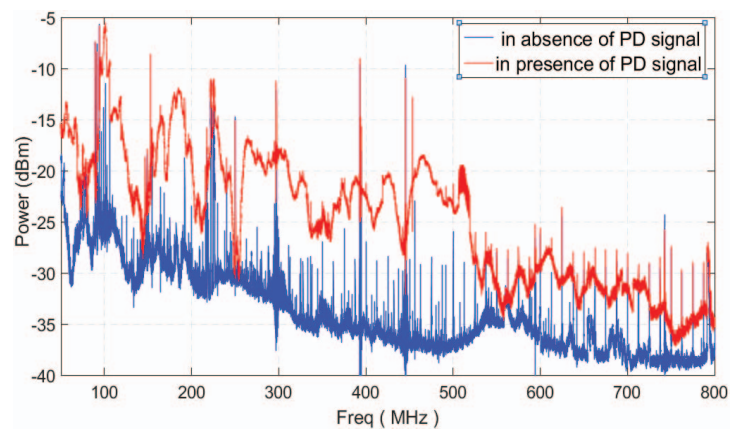

Fig.5. Measured spectrum using SDR.

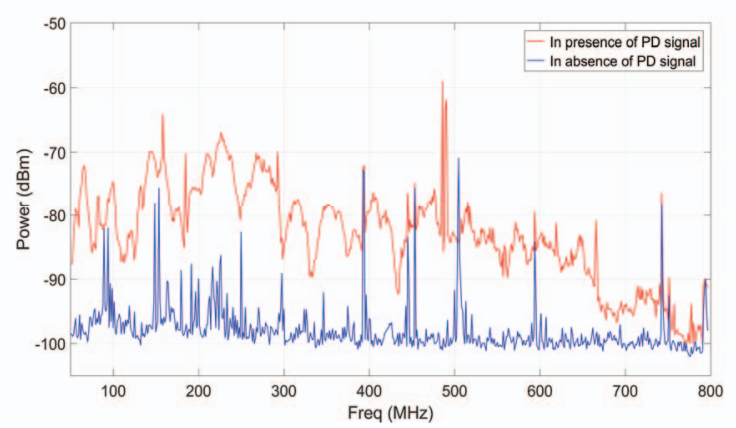

Fig. 6. Measured spectrum using a spectrum analyzer.

\section{CONCLUSION}

The work reported here considers the use of recently developed, low-cost, Software Defined Radio (SDR) technology configured as a spectrum analyzer to measure the radio power spectral density across the frequency band that PD energy might be expected to reside in the smart grid. Due to the cost effeteness of the SDR technology it can be used at the user end for the purpose of PD detection.

\section{REFERENCES}

[1] F. Rahimi \& A. Ipakchi, 'Overview of demand response under the smart grid and market paradigms,' Paper presented at the Innovative Smart Grid Technologies (ISGT), 2010.

[2] H. Mohamed, P. Lazaridis, Umar Khan, D. Upton, B. Saeed, A. Jaber, P. Mather, D. Atkinson, K. Barlee, M. Vieira and I. Glover, "Partial discharge detection using Software Defined Radio”, ICSAE conference, Newcastle, England, October 2016.

[3] C. Gellings, 'Estimating the costs and benefits of the smart grid: a preliminary estimate of the investment requirements and the resultant benefits of a fully functioning smart grid,'”. Electric Power Research Institute (EPRI), Technical Report (1022519), 2011.

[4] EATechnology. What is PD? Partial Discharge. Retrieved 20 Jun. 2014, from http://www.partial-dischargeacademy.com/what-is-partial-discharge.

[5] Y. Zhang, D. Upton, A. Jaber, H. Mohamed, U. Khan, B. Saeed, P. Mather, P. Lazaridis, R. Atkinson, M.F. Q Vieira and I Glover, " Multiple Source Localization for Partial DischargeMonitoring in Electrical Substation," in Antennas \& Propagation Conference (LAPC), Loughborough, 2015, pp. 1-4.

[6] M. D Judd, A. J. Raid, L Yang, B. G. Stewart, and R.A. Fouracre, "A new integrated diagnostic partial discharge monitoring strategy for HV plant items: combining UHF couplers and the IEC60270 standard," in Electricity Distribution, 2005. CIRED 2005. 18th International Conference and Exhibition on, pp. 1-4.

[7] E. T. lorkyase, C. Tachtaatzis, P. Lazaridis I. A .Glover and R. C. Atkinson 'Radio Location of Partial Discharge Sources: A Support Vector Regression Approach" IET Science, Measurement \& Technology, November 2017.

[8] E. T. lorkyase, C. Tachtaatzis, R. C. Atkinson and I. A Glover " Localisation of partial discharge sources using radio fingerprinting technique" Antennas \& Propagation Conference (LAPC), Loughborough, UK, Nov. 2015.

[9] A. Jaber, P. Lazaridis, M. Moradzadeh, I. Glover, Z. Zaharis, M. F.Q. Vieira, M. Judd and R. Atkinson, "' 
Calibration of Free-Space Radiometric Partial Discharge Measurements" IEEE Transactions on Dielectrics and Electrical Insulation, vol. 25, No. 5, pp. 3004-3014, Oct. 2017.

[10] D. Upton, B. Saeed, Umar Khan, A. Japer, P. Lazaridis, H. Mohamed , K. Mistry, P. Mather, E. Iorkyase, C. Tachtatzis, M. Judd, D. Atkinson, K. Barlee, M. Vieira and I. Glover "Wireless Sensor Network for Radiometric Detection and Assessment of Partial Discharge in HV Equipment" $32^{\text {nd }}$ URSI GASS, Montreal, 19-26 August 2017.

[11] A. Gaouda, "Adaptive Partial Discharge monitoring system for future smart grids'. Paper presented at the Industrial Electronics Society, IECON 2013-39th Annual Conference of the IEEE, Vienna, Austria, Nov. 2013.

[12] A. Raid, M. Judd, B. Stewart, and R. Fouracre, "Frequency distribution of RF energy from PD sources and its application in combined RF and IEC60270 measurements," in Electrical Insulation and Dielectric Phenomena, 2006 IEEE Conference on, pp. 640-643, Kansas City, MO, USA Feb. 2006.

[13] A. Raid, M. Judd, B. Stewart, and R. Fouracre, "Comparing IEC60270 and RF partial discharge patterns," in Condition Monitoring and Diagnosis, 2008. CMD 2008.International Conference on, pp. 89-92, Beijing, China Jul. 2008.

[14] Y. Zhang, D. Upton, A. Jaber, U Khan, B, Saeed, H. Ahmed, P. Mather, P. Lazaridis, R. Atkinson, M. Vieria and I. Glover," Radiometric wireless sensor network monitoring of partial discharge sources in electrical substations" Hindawi, International Journal of Distributed Sensor Networks, Vol. 179, pp. 1-9, August 2015.

[15] Y. Zhang, J. M. Neto, D. Upton, A. Jaber, U. Khan, B. Saeed, P. Mather, P. Lazaridis, R. Atkinson, M.F. Q Vieira, I.A. Glover, "An ultrawideband patch antenna for UHF detection of partial discharge." Radio Science Conference (URSI AT-RASC), 2015 1st URSI Atlantic. IEEE, 2015.

[16] Y. Zhang, J. M. Neto, D. Upton, A. Jaber, U. Khan, B. Saeed, P. Mather, P. Lazaridis, R. Atkinson, M.F. Q Vieira, I.A. Glover, "Radiometer monitoring system for partial discharge detection in substation," in Radio Science Conference (URSI AT-RASC), 2015 1st URSI Atlantic, pp. 1-1, 2015.
[17] H. Mohamed, P. Lazaridis, Umar Khan, D. Upton, B. Saeed, A. Jaber, P. Mather, D. Atkinson, K. Barlee, M. Vieira and I. Glover, " Partial discharge detection using low cost RTL-SDR model for wideband spectrum sensing", ICT 2016, Thessaloniki, Greece, May 2016.

[18] R. Stewart, K. Barlee, D. Atkinson, and L. Crockett, "Software Defined Radio using MATLAB \& Simulink and the RTL-SDR", $1^{\text {st }}$ ed., Strathclyde academic media, October 2015.

[19] H. Mohamed, P. Lazaridis, Umar Khan, D. Upton, B. Saeed, P. Mather, D. Atkinson, K. Barlee, M. Vieira and I. Glover, " Partial discharge localization based on received signal strength”, ICAC 2017, Huddersfield, UK, Sep 2017. 